\title{
Space Plasma Effects
}

\author{
Sandro M. Radicella $\left({ }^{1}\right)$, Petra Sauli $\left({ }^{2}\right)$, Norbert Jakowski $\left({ }^{3}\right)$, Daniel Kouba $\left({ }^{2}\right)$, Ana Portillo $\left({ }^{4}\right)$, Miguel \\ Herraiz $\left({ }^{4}\right)$, Hal J. Strangeways $\left({ }^{5}\right)$, Nikolay Zernov $\left({ }^{6}\right)$ and Vadim Gherm $\left({ }^{6}\right)$ \\ (') ARPL, The Abdus Salam ICTP, Trieste, Italy \\ $\left(^{2}\right)$ Institute of Atmospheric Physics, Prague, Czech Republic \\ $\left(^{3}\right)$ Deutsches Zentrum für Luft und Raumfahrt (DLR), \\ Institut für Kommunikation und Navigation, Neustrelitz, Germany \\ $\left({ }^{4}\right)$ Universidad Complutense, Madrid, Spain \\ $\left(^{5}\right)$ University of Leeds, Leeds, UK \\ $\left({ }^{6}\right)$ University of St. Petersbourg, St. Peterbourg, Russia
}

\begin{abstract}
This paper summarizes the activities carried out by WP 3.1 of WG 3 of COST 296 action. The Work Package deals mostly with medium and large ionospheric structures that impacts on GNSS signals. In the research done by this European team, particular attention was given to the ionosphere/space weather monitoring, to the analysis of the variability of the ionospheric plasma during quiet and disturbed conditions and to the characterization of the behavior of low latitudes ionospheric depletions or bubbles and the spatial and temporal gradients of total electron content.
\end{abstract}

Key words ionosphere/space weather monitoring ionospheric variability - ionospheric bubbles ionospheric gradients

\section{Introduction}

Transionospheric radio waves at frequencies up to $10 \mathrm{GHz}$ are affected by the anisotropic plasma density distribution of the ionosphere. In Global Navigation Satellite Systems (GNSS) the ionospheric signal delay may cause range errors of up to 100 meters. In a first order approximation the range error is proportional to the integral of the electron density (TEC) along the ray path and can be mitigated by a simple linear combination of $L 1$ and $L 2$ phases. However, horizontal gradients in the ionospheric

Mailing address: Dr. Sandro M. Radicella, ARPL, The Abdus Salam ICTP, Strada Costiera 11, 34151 Trieste, Italy; e.mail: rsandro@ictp.it electron density and ionospheric irregularities producing phase fluctuations and radio scintillations may cause a significant degradation of navigation signals up to loss of lock. Strong TEC gradients, Traveling Ionospheric Disturbances (TIDs) and phase fluctuations are often correlated with the development of geomagnetic/ionospheric storms. Thus, ionospheric perturbations may cause threats in GNSS applications such as aircraft landing which require a high degree of safety (Safety of Live-SoL). Precise surveying systems may suffer from a loss of accuracy or even loss of lock due to irresolvable phase ambiguities $e . g$. be caused by a decreased signal-to-noise ratio (SNR) or reduced availability of satellites.

\section{Ionosphere/space weather monitoring}

The German Aerospace Center (DLR) has further developed the operational service for spaceplasma and space-weather monitoring through the project SWACI - Space Weather Applications 

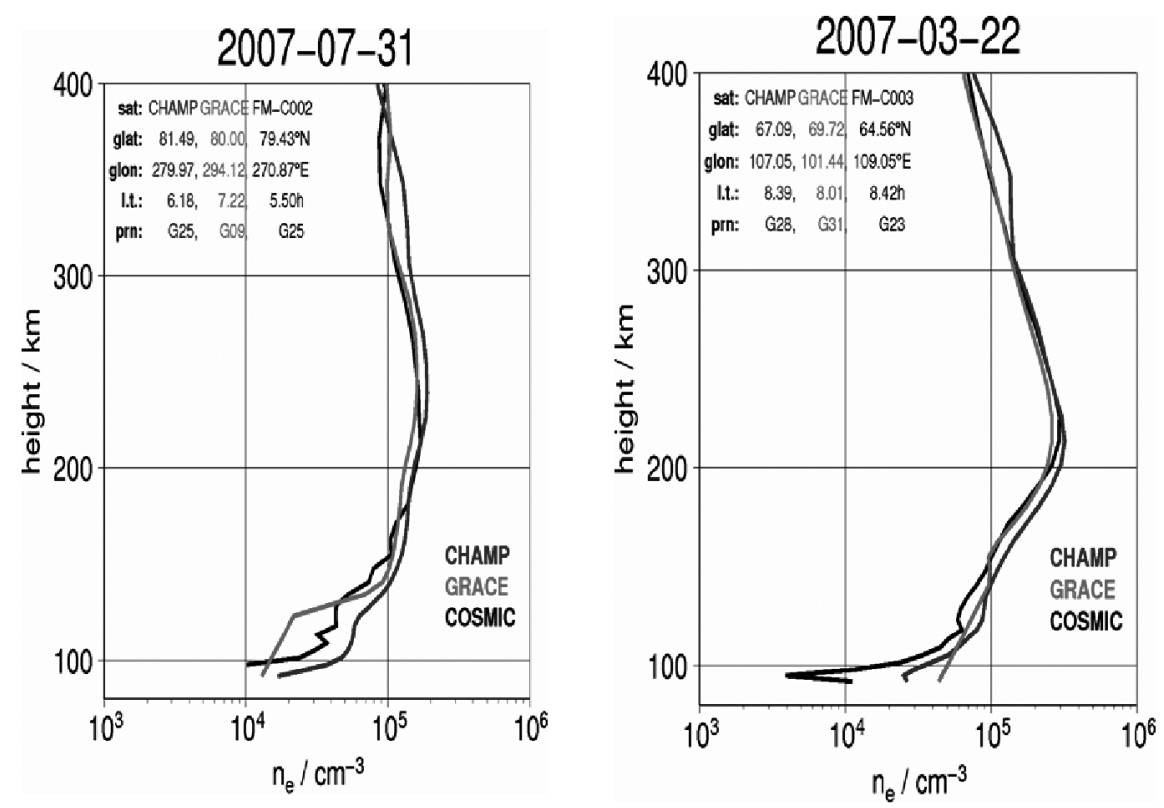

Fig. 1. Comparison of selected IRO profiles derived from CHAMP and GRACE measurements in comparison with COSMIC retrieved profiles (Jakowski et al., 2007a).

Center Ionosphere - http://w3swaci.dlr.de/ (Jakowski et al., 2005c, 2006b, cross reference to WP1.1 and WP3.2 reports). This permanent ionospheric monitoring by ground and space based GNSS techniques provides a powerful data-base for studying plasma effects.

Although still under development, SWACI provides near-real-time TEC maps over Europe ( 5 min time resolution, $1 \mathrm{x} 1 \mathrm{deg}$ horizontal resolution) using ground based GPS data from the European GPS networks. Furthermore, based on earlier developments (Jakowski, 1996), hourly TEC maps from the previous day are available for the European area at the web site http://www.kn.nz.dlr.de/daily/tec-eu/ and for the North Pole area at the web site http://www.kn.nz.dlr.de/daily/tec-np/. (cross reference to WP1.1 report).

Besides the retrieval of vertical electron density from GPS Ionospheric Radio Occultation (IRO) measurements onboard the Geo-Research satellite CHAMP, retrieval algorithms were applied also to GPS radio occultation measurements performed onboard one of the two US-German satellites GRACE. The recent tests were successful, indicating their potential for doubling the number of electron density profiles available per day within the SWACI service.

The retrieval algorithms are based on a tomographic approach dividing the ionosphere and plasmasphere into spherical shells with upward growing thickness and constant electron density inside (Jakowski et al., 2007a).

The validation of IRO derived electron density profiles started by the COST community (Jakowski et al., 2005b; Sadighi et al., 2008) has to be continued (fig. 1).

Whereas GPS radio occultation measurements provide up to about 150 vertical electron density profiles in anti-velocity direction near the orbit plane of the LEO satellite (Jakowski, $2005 a, b)$, topside tracking data for satellite positioning are effectively used to monitor the 3D electron density distribution of the topside ionosphere/plasmasphere near the orbit plane (Heise 
et al., 2002). These data have been used to validate the Topside Sounder Model Profiler (TSMP) developed by Kutiev et al. (2009) or to compare different ionospheric models such as various IRI versions and NeQuick. For the years 2002-2006 a total number of 290,225 profiles were extracted for comparison with the models showing clearly that the old topside model of IRI may deviate up to $500 \%$ from measurements (Mayer and Jakowski, 2007a).

\section{Variability of the ionospheric plasma during quiet conditions}

Variability of the ionospheric plasma affects propagation conditions of GNSS signals. A ground based technique to monitor electron density and motion variability has been used. The main attention was given to the variability in the E region ionosphere (Sauli and Bourdillon, 2008; Kouba et al., 2008). An improvement of the drift evaluation method in the ionosphere was developed for the Pruhonice DPS-4 consisting of a robust height range selection, setting limits on the Doppler frequency shift, and limits control of the echo arrival angle (Kouba et al., 2008).

The monitoring of strong stratification in the $E$ region has been set up. During the summer periods of 2006 and 2007 special campaigns of «Es drift» measurement were performed. The use of the high frequency window provides insight into the plasma motion within the Es layer and clearly shows different behavior of plasma motion in the $E s$ and the regular $E$ layer. Plasma drift velocity shows clear height dependence in the interval 90-150 km. Figure 2 indicates that velocity in the $E s$ layer can reach twice the velocity found for the regular $E$ layer. The largest difference between both velocities is evident on the East and North components.

Direction histograms of the drift velocity are analysed to show the prevailing direction of the plasma in the $F, E$ ans $E s$ layer ionosphere (fig. $3)$. Azimuth angle is measured from North $\left(0^{\circ}\right)$ clockwise. Two velocity windows exceeding 50 $\mathrm{m} . \mathrm{s}^{-1}$ and $100 \mathrm{~m} \cdot \mathrm{s}^{-1}$ are used to show the plasma motion. In the $F$ layer, the two well pronounced peaks located at $180^{\circ}$ (direction to the South) and at $270^{\circ}$ (direction to the West) are shown in the left plot (upper pannel). When only high ve-

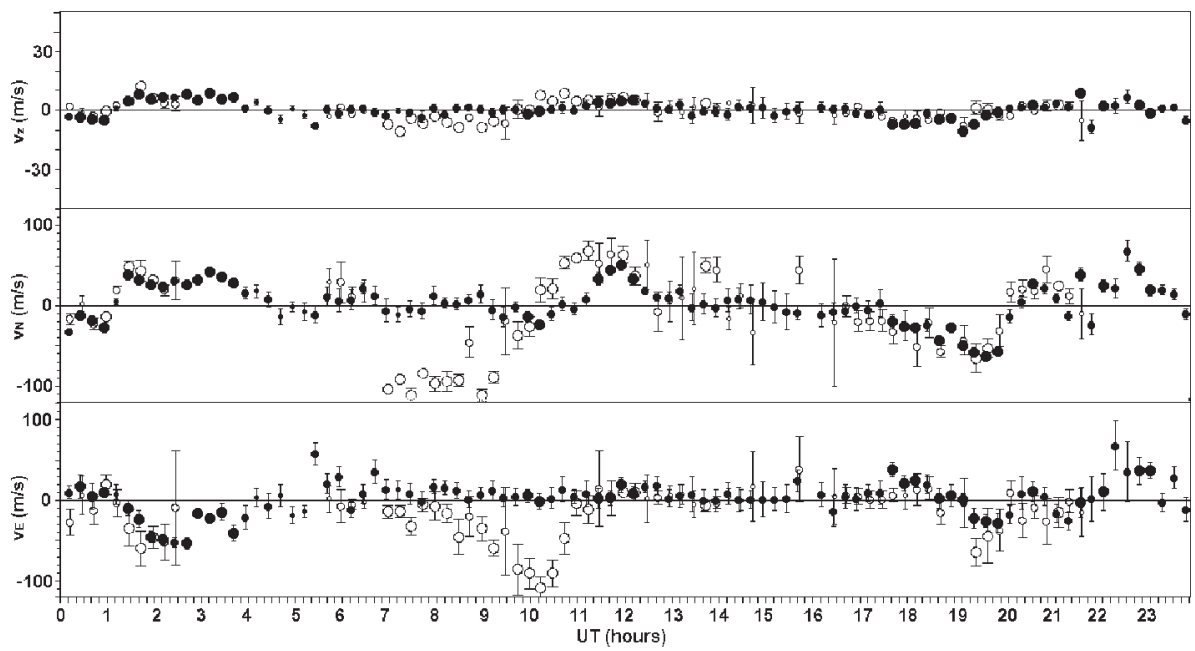

Fig. 2. Example of one-day E-region drift velocity components for Jun 25, 2006. Measurements for the low sounding-frequency window (2-2.6 MHz) are plotted with solid dots and those for the high sounding-frequency window (3.2-4.5 MHz) are plotted with light dots. Three levels of dot size indicate quality of measurement. No smoothing filters were applied to the velocity data. 

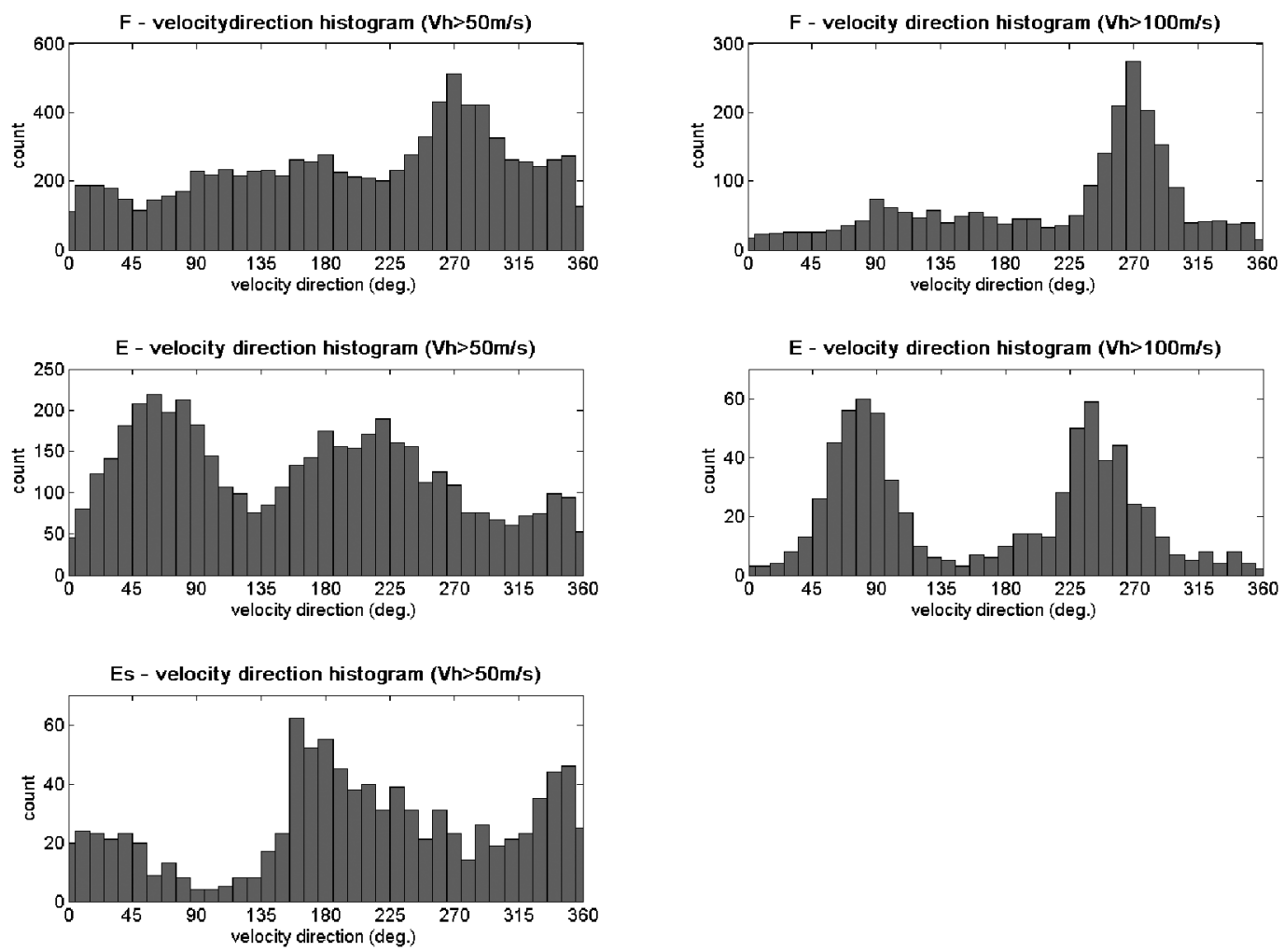

Fig. 3. Direction velocity histograms of the plasma motion close to the $F$ layer peak (upper panels), in the E region in the low frequency window (middle panel), and in the E region in the high frequency window.

locities are taken into account the Southward peak rapidly decreases and Westward peak remains. It is evident that the first peak is mainly formed by slowly moving plasma with velocities below $100 \mathrm{~m} \cdot \mathrm{s}^{-1}$. Fast moving plasma contributes significantly to the formation of the second peak. The second peak is clearly developed even on the histogram containing the highest observed velocities. From the direction histograms of the plasma motion in the $E$ layer (middle and lower pannels) it is evident that plasma moves differently in the regular $E$ layer (low frequency window) and in the sporadic E confirming what was observed using high freguency window. Very similar direction velocity distribution (middle pannel) are observed in the $E$ layer using both velocity windows.

The variability of the height and critical fre- quancy of the sporadic $E$ layer has been analysed over period ranges of hours to several days, covering both the tidal and the planetary oscillation domains. The central-period of the diurnal tidal component of $h E s$ is not exactly 24 $\mathrm{h}$ but it varies between 22 and $26 \mathrm{~h}$ at the planetary wave period. The height of the Es layer is perturbed by the imposed planetary wave. In this mechanism the Es layer is moved up and down by the planetary wave producing a Doppler effect and resulting in a shift of the central-period around $24 \mathrm{~h}$. The excursion of the central-period is related to the vertical velocity perturbation of the Es layer due to the planetary wave. For a central period varying between 22 and $26 \mathrm{~h}$ the peturbation velocities are 0.026 and $-0.022 \mathrm{~m}^{-\mathrm{s}}$, respectively (Sauli and Bourdillon, 2008) (fig. 4). 

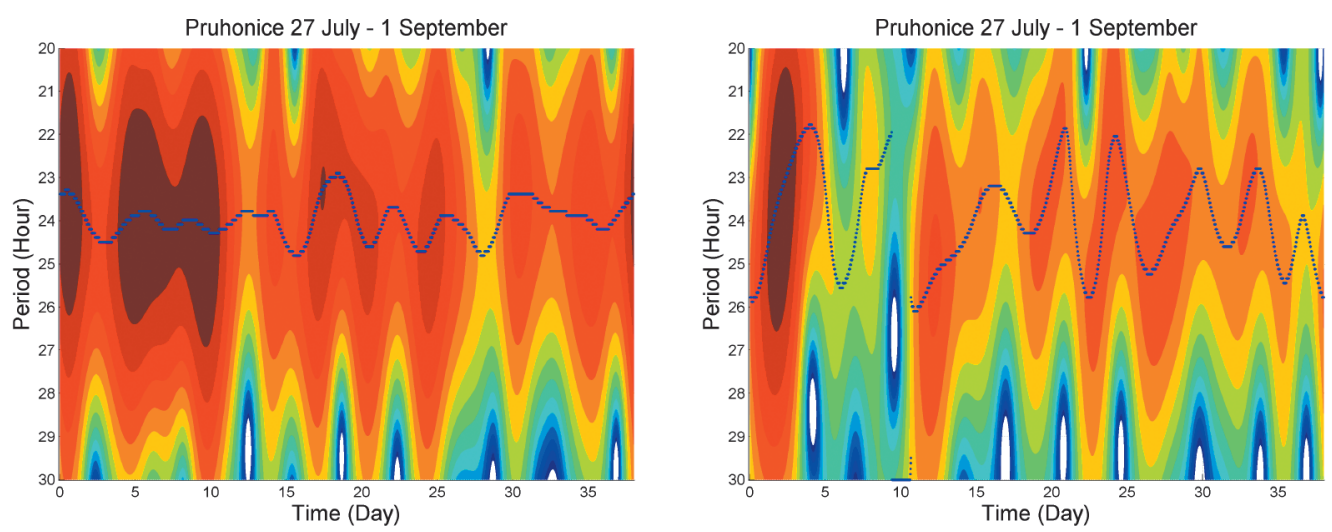

Fig. 4. Wavelet power spectrum of height foEs (left pannel) and h Es (right pannel) in the period range 20-30 h. Blue line indicates position of the maximum.

\section{Variability of the ionospheric plasma during disturbed conditions}

Generally, the ionospheric impact on the propagation of GNSS signals is significantly stronger during ionospheric storms and perturbations. To better quantify this impact, GNSS networks monitor the network integrity by operationally estimating the non-linear error in the output data (Chen et al., 2003).

Integrity monitoring (for residual interpolation and ambiguity resolution) is crucial for the operational quality of network real time kinematics (RTK) systems. The network model integrity (NMI) module is utilised in GNSS reference networks to estimate the potential non-linear residual errors in the generated data transmitted to the user. The relationship between ionospheric perturbations, i.e. space weather conditions, and NMI has been intensively studied (e.g. Jakowski et al., 2005a, Stankov et al., 2006, Stankov and Jakowski, 2007).

Several case studies show that there is a significant increase in the residual error during the onset and main phases of the storm. The NMI variation shows seasonal and diurnal variations which are obviously related to ionospheric features. However, a number of unsolved problems remains. For predicting and mitigating these effects, a more detailed understanding of the rela- tionships between ionospheric perturbations and NMI is needed.

Although the time development of ionospheric storms differs considerably, depending on a large variety of solar-terrestrial conditions, they also show some typical features.

Ionospheric storms depend on a diversity of factors such as current space weather conditions and related processes in the magnetosphere and thermosphere. For this reason statistical studies require a long-term data base for separating potential dependencies, e.g. from storm time, local time, season, solar and geomagnetic activity level. As former statistical studies of ionospheric storms have clearly shown, there is a seasonal dependency of the mean storm time behaviour of TEC patterns (e.g. Titheridge and Buonsanto, 1988, Förster and Jakowski, 2000).

For discussing common features of perturbation induced changes of TEC, so-called differential maps (percentage deviation $\triangle \mathrm{TEC}=$ (TEC - TECmed)/TECmed x 100) are quite useful (Jakowski et al., 2008b). Thus, average storm pattern of TEC over the European area $\left(20^{\circ} \mathrm{W}\right.$ up to $40^{\circ} \mathrm{E}$ and $32.5^{\circ} \mathrm{N}$ up to $\left.70^{\circ} \mathrm{N}\right)$ was deduced as a function of a specially fixed storm time scale over 5 days. The storm time $\mathrm{ST}=00: 00$ is defined by the maximum geomagnetic Dst index rate of change at the storm on- 

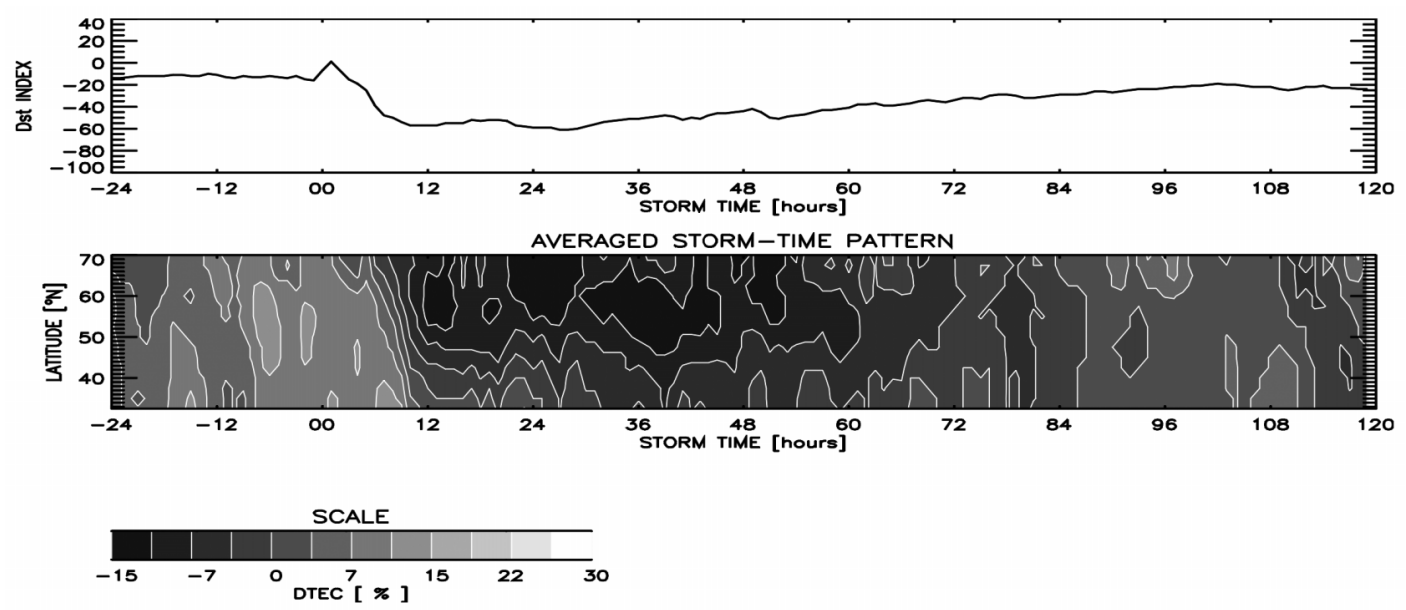

Fig. 5. Superposed TEC storm pattern for summer storms over Europe within years 1995-2004 for severe storms (lower panel) derived at $10^{\circ} \mathrm{E}$ meridian. Upper panel shows averaged Dst values for selected storms with Dst $<-40$ nT.

set phase. Thus, the arithmetic average of superposition of percentage TEC storm pattern of severe storms occurring from 1995 until the end of 2004 indicates significant differences between summer and winter storms. In agreement with former studies the winter storms are characterized by a strong positive phase $(\approx 20 \%$ amplitude) lasting up to 2 days (fig. 5). The subsequent negative phase is weak and focused around $45-60^{\circ} \mathrm{N}$. The summer storms are characterized by a short and less intensive positive phase ( $\approx 10 \%$ amplitude). The subsequent negative phase is well developed at all latitudes $\left(35-70^{\circ} \mathrm{N}\right)$ over 3 days (Jakowski et al., 2008a). As discussed earlier (Foerster and Jakowski, 2000), this behavior is probably due to the direction of prevailing thermospheric winds blowing in summer towards lower latitudes and in winter towards higher latitudes. Thus, perturbation induced winds blowing towards lower latitudes are reduced or stopped in winter and increased in summer.

The observed simultaneous rise of differential TEC at different latitudes at the onset of severe storms indicates the action of an eastward directed electric field which penetrates from high to at least mid-latitudes. The delayed response of the storm pattern towards lower lati- tudes observed a few hours later is a clear indication of the action of storm induced equatorward blowing neutral winds as mentioned above (Arbesser-Rastburg and Jakowski, 2006).

The availability of ground and space based monitoring techniques enables a discussion of ionospheric perturbation features during storms by combining simultaneous ground and space based GPS measurements. Thus, a more detailed view about the perturbation mechanism can be obtained. The temporal and horizontal structure of the high latitude ionosphere at both hemispheres based on $30 \mathrm{~s}$ sampled TEC data from the ground tracking network of the International GNSS Service (IGS) and other services can be deduced (fig. 6).

Whereas the ground based measurements show strong horizontal perturbation induced convection of plasma crossing the pole from day- to night-side, the spaceborne measurements on CHAMP indicate a severe vertical redistribution of the ionospheric plasma during the selected events. Of particular interest is a strong upward lift of ionospheric plasma near plasmapause boundaries (Jakowski et al., 2007b).

Due to their complex interaction with the thermosphere and magnetosphere, the ionos- 

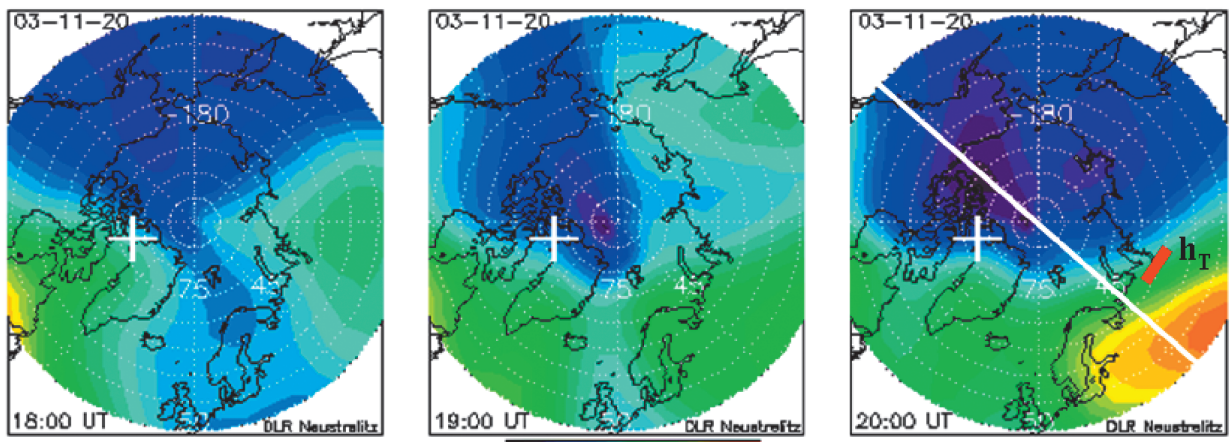

TEC North pole

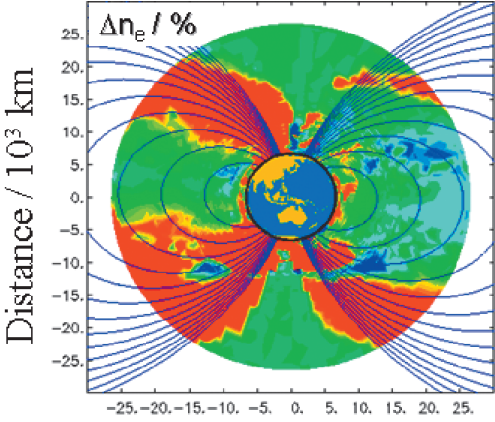

Distance $/ 10^{3} \mathrm{~km}$
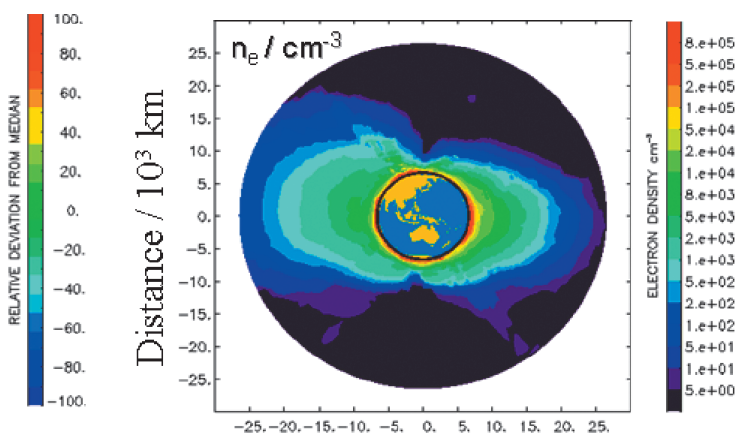

Distance $/ 10^{3} \mathrm{~km}$

Fig. 6. Comparison of ground based TEC maps over the North Pole area (upper panel) on November 20, 2003 with corresponding reconstructions of electron density in the topside ionosphere/plasmasphere in the vicinity of the CHAMP orbit and their deviations from corresponding medians (about 11 LT is to the right side at both plasmasphere plots, trace is marked in the upper panel.

pheric perturbations cannot be described sufficiently well by using geomagnetic activity indices alone. To simplify the quantitative description of ionospheric perturbation processes it is suggested to define ionospheric perturbation indices, that describe essential features of the perturbations. When focusing on GNSS applications, the key ionospheric parameter is TEC. This is not only due to its linear relationship with the first-order ionospheric range error, but also due to its successful use in the ionospheric/plasmaspheric research and its global availability. Therefore, TEC is the outstanding candidate for defining ionospheric perturbation indices. TEC-based indices may be used as input parameters in reliable forecast models and can directly be utilized to improve communications, navigation, and geodetic surveying practices. The new perturbation index (Jakowski et al., 2006), provisionally named Regional Ionosphere Disturbances Index (RIDX), has several formulations in order to better address the nature of perturbation phenomena.

In order to promote the elaboration of such an index, a special task force group has been established within COST 296. A first result of joint activities is a study of ionization gradients over Europe measured by vertical sounding as well as GPS techniques during the «Halloween» storm in 2003 (Jakowski et al., 2008a). One of the main finding is the fact that the strongest ionization gradients are in the NorthSouth direction, exceeding average and East- 


\section{Horizontal TEC Gradients}

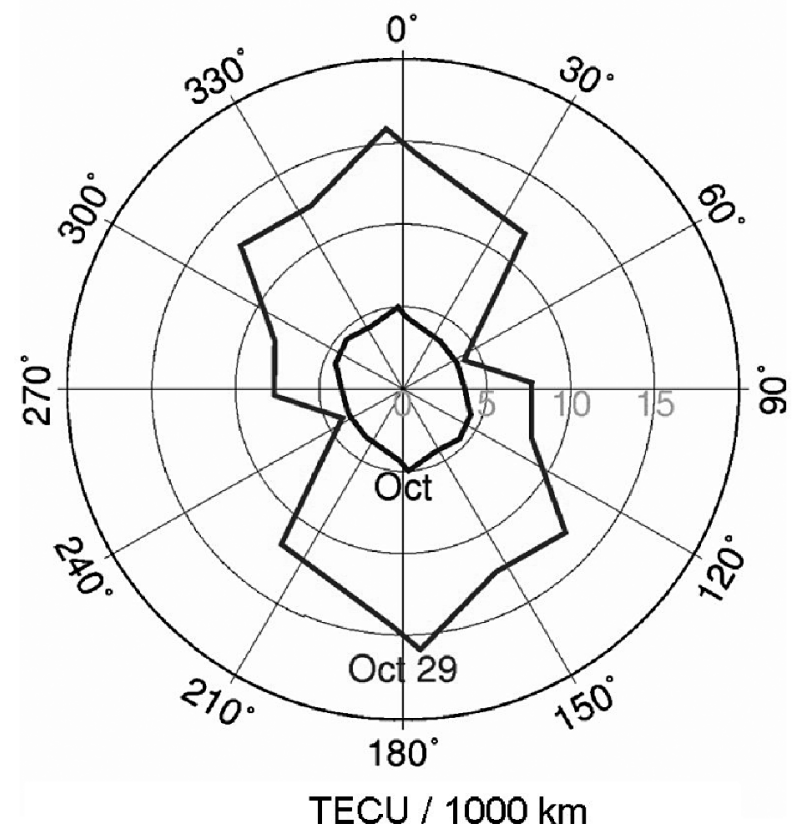

Fig. 7. Azimuth distribution of horizontal ionization gradients of TEC over Europe. Presented is the quadratic mean of TEC (TECU/1000km) on 29 October and for the entire month (Oct) (Jakowski et al., 2008a).

West gradients approximately by a factor of 2 for TEC (see additional work done on TEC gradients in Section 6 of this paper).

The combination of TEC with vertical sounding data enables to estimate the equivalent slab thickness that is a key parameter to study ionospheric perturbation processes. It is recommended to investigate the behaviour of this parameter in more detail in future work.

It has been demonstrated that squared TEC -rate and TEC-gradient values may provide excellent perturbation information for GNSS users. The study favours latitudinal TEC gradient as being a good candidate for defining a perturbation index at least for the European area (fig. 7).

To study the geophysical conditions and characteristics of the ionospheric processes in the auroral zone, GPS radio occultation electron density profile retrievals from CHAMP and COSMIC have been used to extract those vertical profiles which show the absolute maximum of ionization in the $E$-layer height range of $90-150 \mathrm{~km}$. (Mayer and Jakowski, 2007b).

It has to be mentioned that the retrievals from CHAMP and COSMIC provide consistent results. The observations from both data sets clearly show the location of $E$-layer enhanced events being closely related to the auroral oval around the geomagnetic pole. As expected, the number of such events increases with enhanced geomagnetic activity.

Studies of the E-layer dominated ionosphere (ELDI) in the aurora zone have been continued and compared with EISCAT measurements. It is assumed that ELDI is due to electron precipitation in the ionosphere (Mayer and Jakowski, 2007b).

Using Northern Hemisphere TEC data as well as stratospheric re-analyses it has been shown that there probably exist coupling processes that lead to corresponding bursts of 
planetary waves activity in the middle atmosphere and ionosphere, especially at periods and wave numbers known as typical for the quasi-5 and 10-day planetary waves. This coupling is obviously intermittent, and the underlying processes are not yet known (Jacobi et al., 2007). Further indications of the existence of planetary type oscillations in the TEC have been discussed by Borries et al. (2007).

Numerical modelling using an essentially neutral middle atmosphere model shows that neither planetary waves or tides propagate to the ionospheric $F$ region, so that direct planetary waves propagation as well as tidal modulation through these waves, according to the first results, may be ruled out as candidates for the coupling process. Therefore, the question of coupling processes remains open at this stage.

\section{Ionospheric depletions at low latitudes}

Ionospheric plasma depletions, also called Equatorial Plasma Bubbles (EPB), are extended areas of depleted $F$-region plasma density found at low latitudes. They are generated in the equatorial nighttime ionosphere from irregularities and upward plasma drifts and evolve nonlinearly by means of the Rayleigh-Taylor instability. The interest in studying EPBs is that plasma density depletions generate rapid changes in amplitude and phase of radio signals propagating through the depletion. These changes produce ionospheric scintillations that degrade communication and GNSS navigation systems.

Although a large database of depletions observed in GPS derived slant TEC - is available for the American and Indian regions, the African sector has not been studied before the work done in WP3.1 of COST 269 action. An investigation was carried out in this framework by the group of the Universidad Complutense of Madrid in collaboration with the group of the Abdus Salam ICTP in Trieste and the IFAC of Florence. One year (2004) of 10 min calibrated slant TEC from stations belonging to the EGNOS System Test Bed in Africa (Brazaville [BRZ], Doula [DOUA], Lome [LOME] and N'Djamena [NDJA]) and the International
GNSS Service (Ascension Island [ASC1], Malindi [MALI] and Libreville [NKLG]) were used (Portillo et al., 2008). To detect the presence of EPBs a technique was developed to identify the existence of a plasma depletion through the observed decrease of slant TEC. To do this, the method assumes that slant TEC data corresponding to satellite-to-ground paths are time series that can be de-trended. When the de-trended series show decreases that satisfy the same given requirements the EPB is identified. The method is capable of detecting depletions causing slant TEC variations of at least 5 TEC units, equivalent to $0.5 \mathrm{~m}$ path length error in a satellite track.

Using this technique it was possible to characterize the occurrence of EPBs in the African region - during a year of low solar activity - in terms of seasonal variation of number of depletions, apparent duration, slant TEC maximum depth and geographical location of the bubble, assuming that they occur at a pierce point located at $400 \mathrm{~km}$ of altitude. The main conclusions are the following: 1) the occurrence of bubbles is variable from station to station but show well defined peaks at the equinoxes in the stations with a relevant number of depletions incidence (fig. 8); 2) the average duration of the depletion is $90 \mathrm{~min} ; 3$ ) the average depletion is 9 TEC units; 4) the Local time of occurrence is mostly between 19.00 and 23.00. These results are mainly in agreement with those obtained in other regions.

The St. Petersburg University and Leeds University team have developed an effective analytical model for mid-scale (meso-scale) ionospheric inhomogeneities in the background ionosphere occurring either as patches in the high-latitude ionosphere, or bubbles in the low latitude/equatorial ionosphere. This analytical model enables the bubbles or patches to be imbedded in the large-scale background ionosphere in order to investigate the scintillation effects due to presence of these mid-scale structures in the ionosphere. Separate models were required for both the background ionospheric electron density bite-out (bubble) or enhancement (patch) and also the parameters of the imbedded random irregularities.

A simulator capable of determining the 
Detected bubbles in year 2004 using sTEC data from some African ESTB and IGS stations

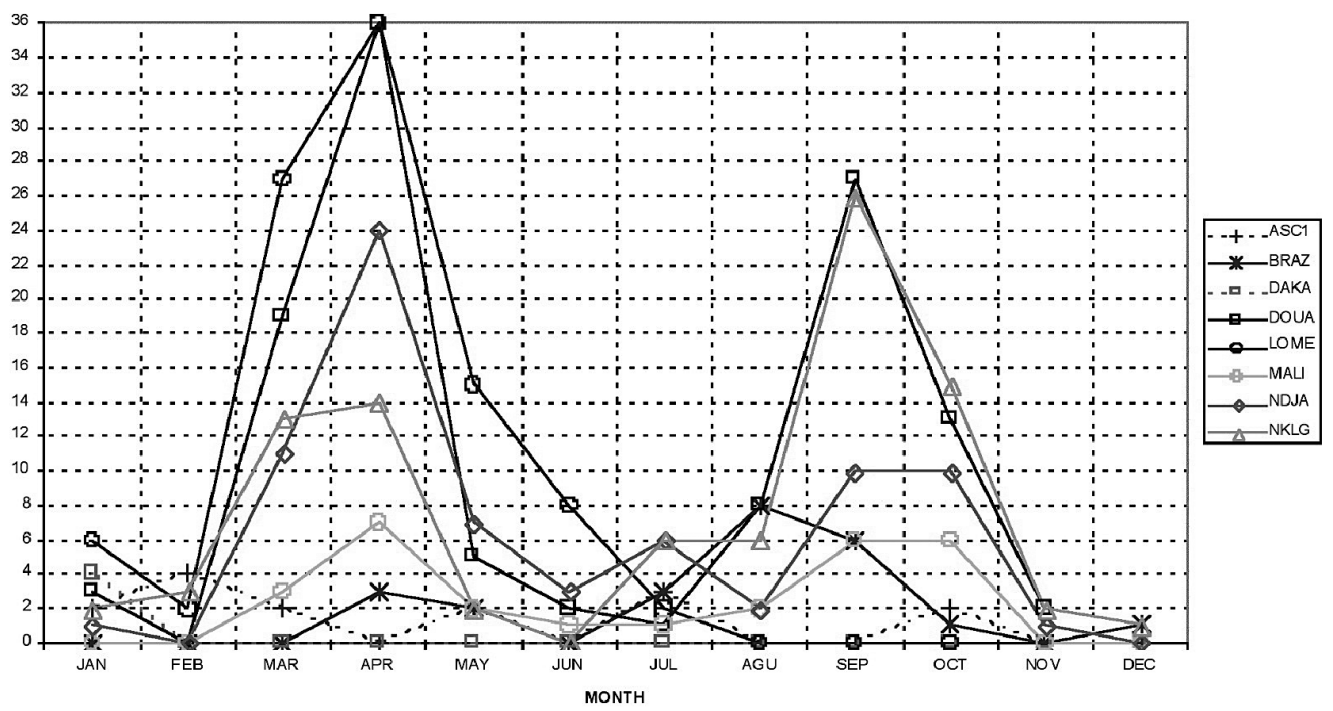

Fig. 8. Seasonal variation of the number of detected bubbles for each station during 2004 .

scintillation on transionospheric paths such as from GPS satellites has been constructed for both types of meso-scale inhomogeneities (Gherm et al., 2007; Strangeways et al., 2007a; 2007b; Zernov et al., 2008a; 2008b). The NeQuick ionosphere model developed by the groups of the Abdus Salam ICTP of Trieste and the University of Graz[http://www.itu.int/ITU$\mathrm{R} /$ study-groups/software/rsg3-p531-electrondensity.zip] was utilized for the large-scale background equatorial ionosphere used in the bubble simulator. Validation of this simulator for through-bubble propagation was possible using data kindly supplied by Dr. Bertram Arbesser-Rastburg (ESAlESTEC) of scintillation measurements in Douala, Cameroon from a number of GPS satellites, including one geostationary. Very good agreement between simulated scintillation effects and measured data for the case of through bubble propagation was achieved as shown in fig. 9 .

The details of the model of the polar patches can be found in Maurits et al. (2008) where the large-scale background polar ionosphere of the University of Alaska, Fairbanks Eulerian
Parallel Polar Ionosphere Model (EPPIM) was employed. For the specification of time-varying small-scale irregularities, superimposed onto the background EPPIM, the full three-dimensional inverse power law spectrum was used. The parameters of the spectrum of the electron density fluctuations, as well as the parameters of meso-scale local polar structures (e.g., patches) were chosen empirically. The simulator enables realistic predictions of the scintillation effects for high-latitude transionospheric propagation for a number of different propagation scenarios for GPS L-band and other UHF transionospheric signals.

\section{Spatial and temporal gradients of TEC}

TEC spatial and temporal gradients are features of the ionosphere that lead to errors in navigation and positioning augmented GNSS Satellite Based Augmentation Systems (SBAS) systems like EGNOS. In most of the conditions found at middle latitudes the effect of gradients is very small under ionospherically quiet condi- 

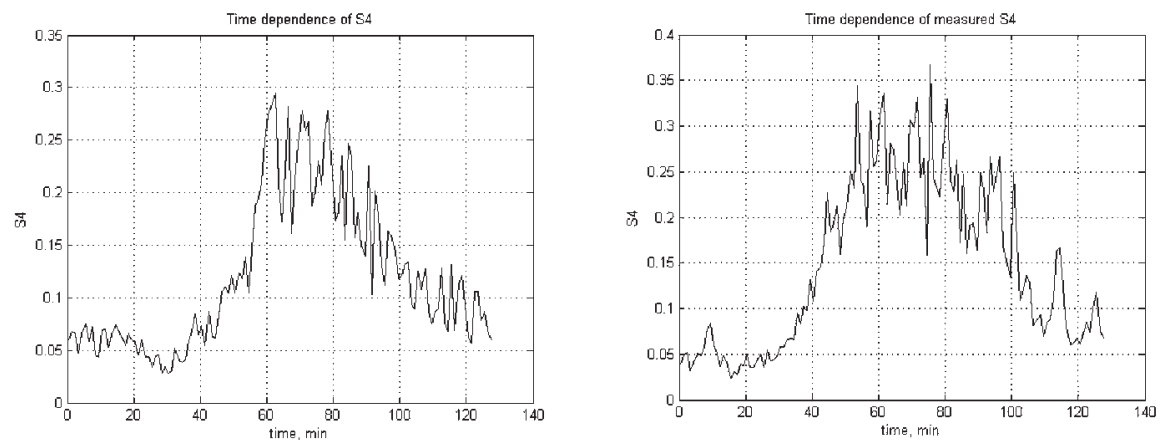

Fig. 9. Comparison between modelled results (left) and actual data (right) of the variation in scintillation index S4 for a GPS signal received at Douala, Cameroon after traversing a bubble.
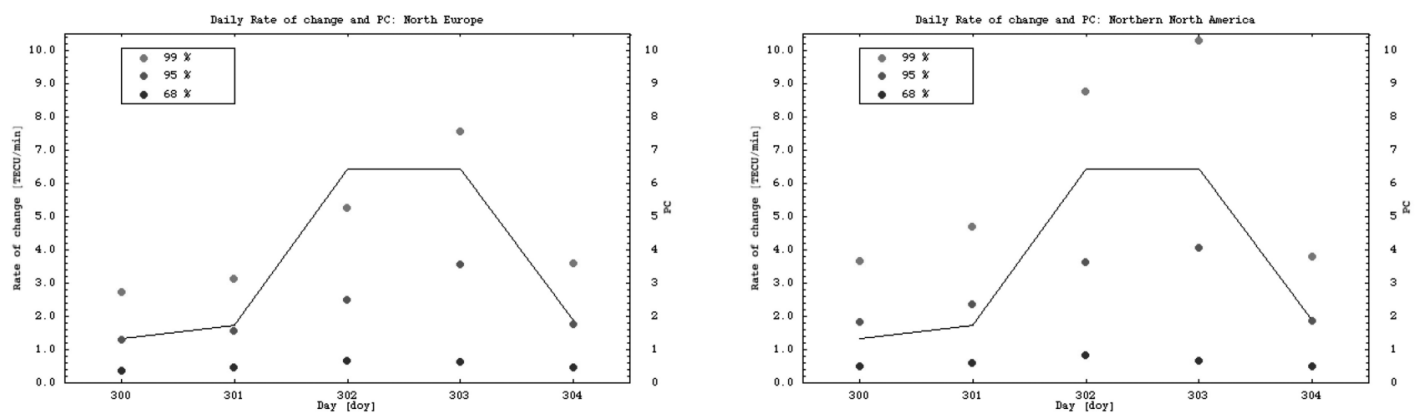

Fig. 10. Absolute values of daily slant TEC rate of change 68, 95 and 99 percentiles and PC index for the period 300-304, 2003.North Europe (left) and Northern North America (right).

tions. Under disturbed conditions like those that occur during geomagnetic storms, gradients at middle latitudes can reach values that degrade the performance of the systems due to the limited spatial density of the monitoring stations or the updating rate of the ionospheric corrections. Both causes can leave the presence of the gradients and their effects in positioning undetected.

An intrinsic problem is the fact that an adequate quantitative estimate of the spatial and temporal gradients of TEC is far for being available at the present. The only objectively measurable parameter is the slant TEC rate of change and it is difficult to assign TEC variations independently to spatial gradients or time variations of the ionosphere. The Abdus Salam ICTP group of Trieste has carried out a study of the behavior of the TEC rate of change as an indicator of TEC variations that affect SBAS operations in collaboration with IFAC of Florence.

GPS derived slant TEC rate of change has been studied to investigate the effect of a strong geomagnetic storm on this parameter as a function of geographical location (Coïsson et al., 2007a). The period chosen corresponds to DOY 300 to 304 of 2003 (27 to 31 October) characterized by large excursions of the geomagnetic activity Ap index, that ranges from 11 to 203. The same period presented a well defined SITEC in the sun-lighted part of the Earth. The analysis has been done using data from 19 IGS stations reasonably well distributed worldwide between \pm 60 o modip, to avoid the statistical unbalance introduced by geographical areas with 


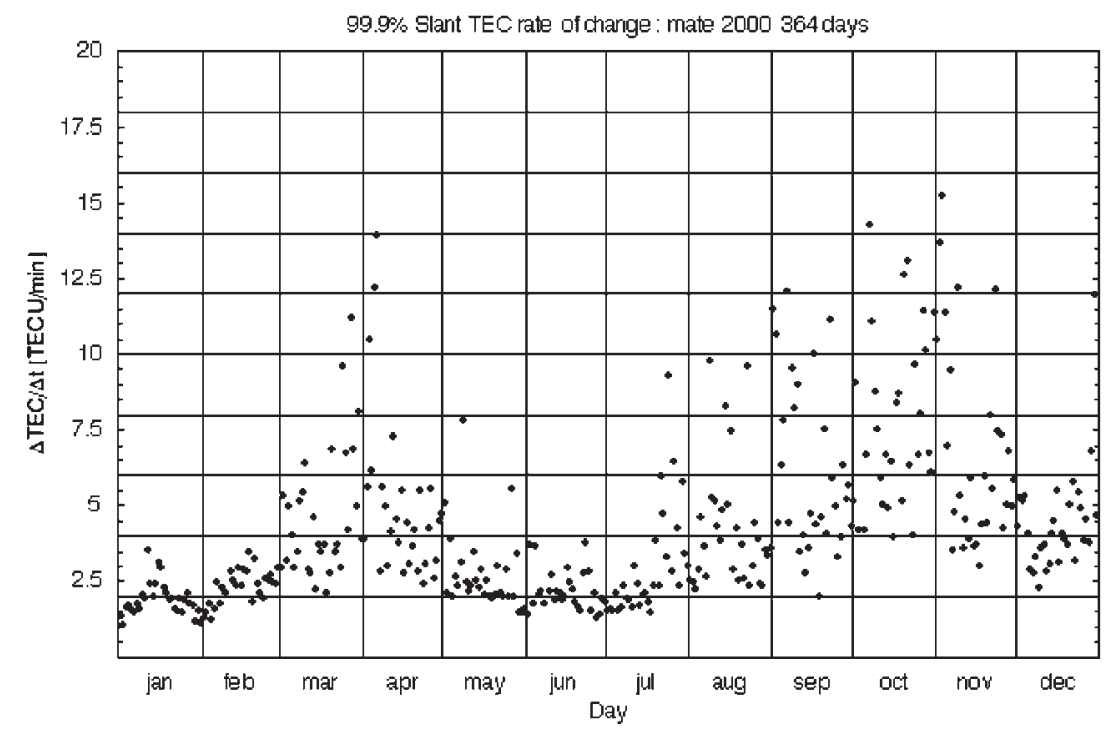

Fig. 11. Absolute slant TEC rate of change (99.9 percentile) or each day of 2000 for Matera.

a high concentration of stations like Europe or United States.

Particular attention has been given to the geographical behavior of the 95 and 99 percentile of the statistical distribution of slant TEC rate of change. A clear modip dependence of the values of the statistical percentiles is found for the geomagnetic quiet day of the period studied. This dependence disappears during the geomagnetic storm days being replaced by a well defined longitudinal one with the largest effect of the storm over the American continents and much reduced effects in other longitudinal sectors (fig. 10). These results have been confirmed extending the analysis to data from a larger number of stations unevenly distributed over the Earth.

Investigating the behavior of slant TEC rate of change, over the European-African sector, very large values were found using data from IGS stations located at middle latitudes, during quiet days at high solar activity (Coïsson $e t$ al., 2007b). As an example, data from the IGS station of Matera (Geog. Lat. 40.6 $)$; Geog. Lon. $16.7^{\circ}$ ) show that for 24 days of the year 2000 the 99.9 percentile exceeded $10 \mathrm{TECu} / \mathrm{min}$. All but 2 of the 24 days were quiet days with Ap below 25 (fig. 11).

\section{Other contributions}

Additional research work was carried out in the framework of Work package 3.1 by $T$. Gulyaeva of the Russian Federation and by the team of the Middle East Technical University of Ankara, Turkey, under the direction of E. Tulunay.

T. Gulyaeva compared total electron content extracted from GPS-JPL ionospheric maps with TOPEX/JASON data for half solar cycle discussing the differences found.

E. Tulunay and his team have initiated an investigation on the integration of their Neural Network plus Genetic Programming approach to forecasting $f o F 2$ to the NeQuick model. 


\section{Conclusions}

This paper shows the substantial advances obtained in the framework of Working Package 3.1 towards a better understanding of the impact of medium and large scale ionospheric variations on the GNSS signals.

These advances relates mainly to:

- space weather/ionospheric monitoring;

- ionospheric variability of drift velocities at different height in the ionosphere during quiet conditions;

- the relationship between ionospheric pertubations and GNSS network model integrity;

- the proposal for a ionospheric perturbation index, usable for GNSS operations, based on TEC and vertical soundings variations;

- the development and use of a technique to detect Equatorial Plasma Bubbles related to ionospheric scintillations;

- development of a simulator capable of determining the effect of ionospheric bubbles and patches on GNSS signals by imbedding models of these structures into a background ionosphere model;

- characterization of TEC rate of change, as an indicator of the TEC gradients that impacts on GNSS operations.

\section{REFERENCES}

ARBESSER-RAstBURG, B. and N. JAKOWSKI (2006): Effects on Satellite Navigation, chapter 13, in Space Weather Physics and Effects, edited by V. BothMER and I. DAGLIS, ISBN: 3-540-23907-3.

Borries, C., N. JAKOWSKI, CH JACOBI, P. HoFFMANN and A. Pogoreltsev (2007): Spectral analysis of planetary waves seen in ionospheric total electron content (TEC): First results using GPS differential TEC and stratospheric reanalyses, J. Atmos. Sol.-Terr. Phys., doi:10.1016/j.jastp.2007.02.004.

Chen, X., H. Landau and U. Vollath (2003): New tools for network RTK integrity monitoring, in Proceedings of the ION GNSS 2003, 9-12 September 2003, (Portland OR, USA), 1355-1360.

CoÏsson, P., S.M. Radicella, L. Ciraolo and B. Nava (2007a): Geographical variations of slant TEC rate of change during different geomagnetic activity conditions, in Proceedings of the IBSS 2007, edited by P. DOHERTY, (Boston).

CoÏsson, P., S.M. Radicella, B. Nava and L. Ciraolo (2007b): Large TEC rate of change at middle latitudes during geomagnetic quiet conditions at high solar ac- tivity, Proceedings of the IBSS 2007, edited by P. DoHERTY, (Boston).

FÖRSTER, M. and JAKOWSKI, N. (2000): Geomagnetic Storm Effects on the Topside Ionosphere and Plasmasphere: A Compact Tutorial and New Results, Surveys in Geophysics, 21 (1), 47-87.

GHERM, V.E., N.N. ZERNOV and H.J. STRANGEWAYs (2007): Modelling of the effect of strong scintillation on GPS Signals due to plasma bubbles in the low-latitude ionosphere, (presented at COST 296/IRI meeting in Prague, Czech Republic, 10-14 July, 2007 and published on the conference website).

Heise, S., N. Jakowski, A. Wehrenpfennig, Ch. Reigber and H. LÜHR (2002): Sounding of the Topside Ionosphere/Plasmasphere Based on GPS Measurements from CHAMP: Initial Results, Geophysical Research Letters, 29 (14), doi:10.1029/2002GL014738, 2002.

Jacobi, C., N. Jakowski, A. Pogoreltsev, K. Fröhlich, P. HofFMANn and C. Borries (2007): The CPW-TEC project: Planetary waves in the middle atmosphere and ionosphere, Adv. Radio Science, 5, 393-397.

JAKOWSKI, N. (1996): TEC Monitoring by Using Satellite Positioning Systems, in Modern Ionospheric Science, edited by H. KoHL, R. Rüster and K. SCHLEGEL, (EGS, Katlenburg-Lindau, ProduServ GmbH Verlagsservice, Berlin), pp. 371-390.

Jakowski, N., S.M. Stankov, D. Klaehn, J. RuefFer, B. HUCK and A. RIETDORF (2005a): Ionospheric impact on the performance of GNSS reference networks, in Proceedings of the European Navigation Conference, (1922 July 2005, Munich, Germany, Paper No. ENCGNSS2005-527a).

Jakowski, N., K. Tsybulya, J. Mielich, A. Belehaki, D. Altadill, J.C. Jodogne and B. Zolesi (2005b): Validation of GPS Radio Occultation Measurements on CHAMP by Vertical Sounding Observations in Europe, in, Earth Observation with CHAMP, Results from Three Years in Orbit, edited by C. REIGBER, H. LÜHR, P. SChwintzer and J. WickerT, (Springer-Verlag, Berlin), pp. 447-452.

JAKOWSKI, N., S.M. STANKOV and D. KLAEHN (2005c): Operational space weather service for GNSS precise positioning, Annales Geophysicae, 23, 3071-3079.

JAkowski, N., S.M. Stankov, S. Schlueter and D. KLAEHN (2006): On developing a new ionospheric perturbation index for space weather operations, Advances in Space Research, 38 (11), 2596-2600.

Jakowski, N., C. Mayer, J. Wickert, S. Heise and W. KÖHLER (2007a): Retrieval of electron density profiles from GRACE radio occultation data, Joint International GRACE Science Team Meeting and DFG SPP 1257 Symposium, (15-17 Oct. 2007, GFZ Potsdam).

JAKOWSKI, N., V. WILKEN and C. MAYER (2007b): Space weather monitoring by GPS measurements on board CHAMP, AGU Space Weather, 5, S08006, doi:10.1029/2006SW000271.

Jakowski, N., J. Mielich, C. Borries, L. CAnder, A. Krankowski, B. Nava and S. M. Stankov (2008a): Large scale ionospheric gradients over Europe observed in October 2003, Journal of Atmospheric and SolarTerrestrial Physics, doi:10.1016/j.jastp.2008.03.020.

Jakowski, N., C. Mayer, C. Borries and B. Nava (2008b): Ionospheric storm characteristics and capabilities for 
describing their potential impact on radio systems, Ionospheric Effects Symposium, (13-15 Mai, 2008, Alexandria, USA).

Kutiev, I., P. Marinov, A. Belehaki, B. Reinisch and N. JAKOWSKI (2009): Reconstruction of topside density profile by using the topside sounder model profiler and digisonde data, Advance in Space Research, 43 (11).

Kouba, D., J. Boska, I.A. Galkin, O. Santolik and P. SAULI (2008): Ionospheric drift measurements: Skymap points selection, Radio Science, $\mathbf{4 3}$.

MAYER, C. and N. JAKOWSKI (2007a): Comparison of the IRI-2007 Topside Electron density with CHAMP and COSMIC/Formosat-3 Data, (IRI/COST 296 Workshop, 10-14 July 2007, Prague, Czech Republic).

MAYER, C. and N. JAKOWSKI (2007b): Observation of Ionospheric Effects in the Aurora Zone using CHAMP and COSMIC/Formosat-3 Data, (13th International EISCAT Workshop and Radar School 6-10 August 2007, Mariehamn, Åland Islands, Finland).

Maurits, S.A., V.E. GHERM, N.N. Zernov and H.J. STRANGEWAYS (2008): Modeling of scintillation effects on high-latitude transionospheric paths using ionospheric model (UAF EPPIM) for background electron density specifications, Radio Science, 43, RS4001, doi:10.1029/2006RS003539.

Portillo, A, M. Herraiz, S.M. Radicella and L. CiraoLO (2008): Equatorial plasma bubbles studied using African slant total electron content observations, $J$. Atmos. Solar-Terr. Phys, 70, 907-917.

SADIGHI, S., P.T. JAYACHANDRAN, N. JAKOWSKI and J.W. MaCDOUGALL (2008): Validation of the CHAMP radio occultation data using CADI in the polar regions, (paper presented at URSI General Assembly, Chicago, 916 August 2008).

Sauli, P. and A. Bourdillon (2008): Height and critical frequency variationsof the sporadic-E layer at midlatitudes, Journal of Atmospheric andSolar-Terrestrial Physics, doi:10.1016/j.jastp.2008.03.016.
Stankov, S.M., N. Jakowski, K. Tsybulya and V. WILKEN (2006): Monitoring the generation and propagation of ionospheric disturbances and effects on GNSS positioning, Radio Science, 41, RS6S09, doi:10.1029/2005RS003327.

STANKOV, S.M. and N. JAKOWSKI (2007): Ionospheric effects on GNSS reference network integrity, Journal of Atmospheric and Solar-Terrestrial Physics, 69, 485-499.

STRANGEWAYS, H.J., V.E. GHERM and N.N. ZERNOV (2007a): Modelling and mitigation of the effect of ionospheric scintillations on GPS due to time-varying electron density irregularities and plasma bubbles, invited paper at the workshop on Global Navigation Satellite Systems (GNSS): problems, vulnerabilities and solutions, Baska, Krk Island, Croatia, 12-14 September 2007.

Strangeways, H.J., V.E. GHERM and N.N. ZERNOV (2007b): Modeling and mitigation of the effect of scintillations on GPS, (invited paper at 49th International Symposium ELMAR-2007, 12-14 September 2007, Zadar, Croatia. Conference Proc.) pp. 69-73, (available online in IEEE Xplore) doi:10.1109/ELMAR.2007.4418802.

TitheRIDGE, J.E. and M.J. Buonsanto (1988): A comparison of Northern and Southern Hemisphere TEC Storm Behaviour, J. Atmos. Terr. Phys., 50, 763-780.

ZERNOV, N.N., V.E. GHERM and H.J. STRANGEWAYS (2008a): The scintillation propagation model for the effects of scintillation on transionospheric paths traversing midscale ionospheric inhomogeneities, in COST 296 Workshop «Ionospheric scintillation: Scientific aspects, Space weather, Application and services», (Nottingham, UK, 20-22 February, 2008).

ZERNOv, N.N., V.E. GHERM and H.J. STRANGEWAYs (2008b): On the Effects of Scintillation on the Transionospheric Paths of Propagation, (paper 6B-6 presented at the International Ionospheric Effects Symposium, Alexandria, Washington DC, USA, May 13-15, 2008. Published in the Conference Proceedings). 